\title{
Perceptions vs. recommendations: A rangeland decision-making dilemma
}

\author{
R. C. ROWAN, HOWARD W. LADEWIG, AND LARRY D. WHITE
}

\begin{abstract}
Authors are research associate, Department of Rangeland Ecology and Management, Texas A\&M University, College Station 77843-2126; professor and Extension Program Leader, Texas Agricultural Extension Service, College Station 77843-2141; and professor and Extension Range Specialist, Texas Agricultural Extension Service, College Station 77843-2126. At the time of the research, Rowan was Extension Graduate Assistant, Department of Rangeland Ecology and Management, Texas A\&M University.
\end{abstract}

\begin{abstract}
This paper analyzes subjective perceptions of Texas ranchers concerning management decision-making to obtain insight for improving technology transfer. Correlations among variables from a 1990 mail questionnaire were transformed by principal component analysis into a small number of "new" variables representing unobservable patterns of behavioral similarities. Two principal components explained variability in rancher's perceptions for each of the areas of interest: stocking rate factors, grazing program benefits, and weed/brush treatment techniques. Stocking rate and grazing program components were each characterized by traditional and nontraditional factors. Ranchers perceived the primary benefit from instituting a grazing program to be improved livestock performance (traditional grazing component 1 ). Some modification of ranchers' perceptions about the primary benefits of grazing programs is indicated. Weed/brush decisionmaking was characterized by information-source and economic factors. The information-source component was defined by the importance of advice from neighbors and fear of treatment methods. Because these tend to be negative perceptions, both of these variables have the potential for restricting adoption of weed/brush technology.
\end{abstract}

Key words: perceptions, principal component analysis, factor analysis, decision-making, correlation, survey analysis

Decisions made by ranchers to initiate rangeland practices, such as weed/brush control, are often based on perceptions of current or past resource conditions. For example, Rowan and White (1994) reported that Texas ranchers planned no treatment of rangeland if brush encroachment did not exceed $12 \%$ of the total land area. A rancher's perception of existing brush levels may not coincide with actual amounts. Although the perception that one's ranch contains $12 \%$ brush may constitute truth for the rancher, it may or may not be "true." An estimate of the true value could be derived by measuring brush canopies along several transects. However, it is slightly more difficult to measure the perceived importance of a rancher's past experience in establishing livestock stocking rates. Although many of the important factors in rancher decision-making are subjective, these factors may help in determining patterns of consistency in rancher's responses based on their perceptions.

Since perceptions cannot be directly observed, a person's thoughts can be probed by soliciting responses to specific questions. Ordinal

Research was funded by the USDA Soil Conservation Service and the Texas Agricultural Extension Service. Authors wish to thank Mr. Paul Pope, Extension Computer Specialist, for his contributions to data analysis.

Manuscript accepted 22 Feb. 1994.
Likert-type responses (e.g., strongly disagree, disagree, neutral, agree or strongly agree) often contain valuable information about human opinions or preferences manifested by various unobservable patterns. The ordered levels may be assigned numerical values from which means can be calculated for each question sublevel. Unfortunately, measures of central tendency do not accurately represent the dimensionality in behavioral similarities because they fail to account for correlation between the sublevel responses. The principle of dimensionality distinguishes between variables (i.e., range practices) that would or would not be commonly shared by a group of ranchers. One procedure for manipulating subjective data to determine ranchers' knowledge and use of rangeland practices is through principal component analysis (PCA).

Principal component analysis along with common factor analysis are procedures for linear transformation of data (Dunteman 1989). Quite often, the sublevels of a question are numerous and the sheer numbers of variables are cumbersome in multivariate modeling. In other instances, question sublevels are highly correlated with each other and their inclusion as independent variables in regression analysis leads to multicollinearity problems (Dunteman 1989). PCA addresses these 2 data problems by transforming the correlation matrix of all sublevel variables into a "new" subset of unobserved variables (Loehlin 1987) which are uncorrelated linear combinations of components or factors.

Linear combinations are used widely, often without recognizing that the resulting score is a composite of variable scores. For example, academic test scores are composites of integers, generally with equal weighting per question. Each question of a 20 question exam, with a possible score of 100 , may be assigned a potential score of 5 . However, if one or more questions are more complex or difficult, professors may assign more weight to those questions and, thus, would contribute a greater percentage toward the total score than questions with lower weighting. Observed responses would be measured for each individual test question and the linear composite called an overall test score. An overall score of, say, 83 could be called "student knowledge" or "teacher effectiveness" or other arbitrary labels for the unobserved dimension being measured. This analogy can be extended to ordinal scale data collected by surveys.

The purpose of this research was to determine component pattern and structure of factors associated with stocking rate, grazing program, and weed/brush decision-making. The relevant questions were: (1) whether one or more dimensions were necessary to explain each area of decision-making, (2) whether the dimensions (components) were interpretable, and (3) whether the component structure was consistent with accepted range management recommendations. 
Table 1. Sublevel response variables for 3 survey questions, rated by respondents on a scale from 1 to 4 (not important to very important).

How important are the following factors in establishing the animal livestock stocking rate for rangeland on this ranch?

1. Forage considerations

2. Livestock considerations

4. Past experience

3. Wildlife considerations

5. Weather

6. Other people's advice

How important are the following benefits for a grazing program to perform successfully?

1. Improved amount or kind of forage

2. Increased or decreased forage use

3. Reduced weeds and/or brush

4. Improved grazing distribution

5. Improved livestock performance

6. Increased or maintained livestock numbers

How important are the following items when deciding what treatment techniques to use to control weeds and brush?
1. Brush/weed kind, height or density

2. Soil type

3. Cost of treatment

4. Availability of professional applicator

5. Existing ranch application equipment

6. Projected economic returns

7. Advice from agencies
7. Reduced feed purchases

8. Reduced drought impact

9. Reduced labor requirement

10. Improved wildlife habitat

11. Obtain other people's approval (a)

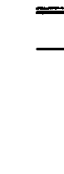

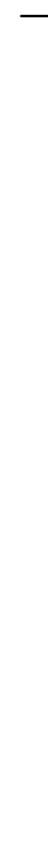

8. Advice from neighbors

9. Proximity to crops

10. Government restrictions or cost share

11. Result demonstrations

12. Fear of treatment method

13. Real estate value

14. Personal experience.

\section{Methods}

Likert-type questions representing 3 areas of concern from preliminary analysis of survey results (Hanselka et al. 1990) were chosen for principal component analysis (Table 1): livestock stocking rate factors (6 variables), successful grazing program benefits ( 11 variables), and important weed/brush treatment techniques (14 variables).

Ratings for each question sublevel ranged from 1 (not important) to 4 (very important). The principal component procedure attempted to identify a subset of variables which a portion of the respondents had in common. "Loading" values were derived from the correlation matrix between sublevel variables and principal components. When squared and summed across each variable within each principal component (columns), the resultant number is called an eigenvalue. Eigenvalues divided by the number of variables within the component, multiplied by 100 , gives the percentage of total variance explained by that component. Because the variables were standardized, each variable theoretically contributed a unit variance of 1 to total variance. For example, a question with 6 sublevels would have a total variance of 6 , distributed among the principal components.

Components with eigenvalues greater than 1 (i.e., explaining more variance than a single variable) were rotated using the Varimax procedure and compared against unrotated components for interpretable patterns. Relative size of the loadings among variables and across components were keys to interpretation. High loading values on some variables of a component or low or negative loadings on others suggested clusters of respondents similarly perceiving the importance of those variables. Consequently, it was not only a particular variable loading highly on a component, but the rank order of the variables within each component which gave components their interpretive meaning.

A Reliability Coefficient, designated theta $(\theta)$, was calculated on the scores to determine the effectiveness of components as independent variables in subsequent analytical procedures, such as ordinary leastsquares regression. The Reliability Coefficient is a special case of Cronbach's Alpha Coefficient (Carmines and Zeller 1979). For a dis-
Table 2. Means and standard deviations of variables measuring the importance of livestock stocking rate factors, grazing program benefits, and weed/brush treatment techniques.

\begin{tabular}{|c|c|c|c|}
\hline \multicolumn{2}{|c|}{ Variables } & mean & sd \\
\hline \multicolumn{4}{|c|}{ Stocking Rate Factors: } \\
\hline 1. & Forage considerations & 3.72 & 0.61 \\
\hline 2. & Livestock considerations & 3.49 & 0.74 \\
\hline 3. & Wildlife considerations & 2.37 & 1.06 \\
\hline 4. & Past experience & 3.43 & 0.75 \\
\hline 5. & Weather & 3.68 & 0.64 \\
\hline 6. & Other people's advice & 1.82 & 0.94 \\
\hline \multicolumn{4}{|c|}{ Grazing Program Benefits: } \\
\hline 7. & Improved amount or kind of forage & 3.62 & 0.62 \\
\hline 8. & Increased or decreased forage use & 3.23 & 0.73 \\
\hline 9. & Reduced weeds and/or brush & 3.28 & 0.84 \\
\hline 10. & Improved grazing distribution & 3.29 & 0.73 \\
\hline 11. & Improved livestock performance & 3.50 & 0.66 \\
\hline 12. & Increased or maintained livestock numbers & 3.32 & 0.74 \\
\hline 13. & Reduced feed purchases & 3.35 & 0.77 \\
\hline 14. & Reduced drought impact & 3.48 & 0.69 \\
\hline 15. & Reduced labor requirement & 2.88 & 1.02 \\
\hline 16. & Improved wildlife habitat & 2.57 & 1.06 \\
\hline 17. & Obtain other people's approval & 1.48 & 0.80 \\
\hline \multicolumn{4}{|c|}{ Weed/brush Treatment Techniques: } \\
\hline 18. & Brush/weed kind, height or density & 3.46 & 0.78 \\
\hline 19. & Soil type & 2.56 & 1.05 \\
\hline 20. & Cost of treatment & 3.50 & 0.76 \\
\hline 21. & Availability of professional applicator & 2.35 & 1.13 \\
\hline 22. & Existing ranch application equipment & 2.60 & 1.10 \\
\hline 23. & Projected economic returns & 3.25 & 0.87 \\
\hline 24. & Advice from agencies & 2.25 & 1.06 \\
\hline 25. & Advice from neighbors & 1.75 & 0.89 \\
\hline 26. & Proximity to crops & 2.55 & 1.24 \\
\hline 27. & Government restrictions or cost share & 2.39 & 1.20 \\
\hline 28. & Result demonstrations & 2.56 & 1.08 \\
\hline 29. & Fear of treatment method & 2.16 & 1.12 \\
\hline 30. & Real estate value & 2.45 & 1.15 \\
\hline 31. & Personal experience & 3.29 & 0.83 \\
\hline
\end{tabular}

cussion of Cronbach's Alpha and its application, see Cronbach (1951). The equation for calculating the Reliability Coefficient was as follows:

(Eq. 1) $\quad \theta=(\mathrm{N} / \mathrm{N}-1)(1-1 / \lambda)$

where $\theta$ represents theta,

$\mathrm{N}$ equals the number of items or variables, and

$\lambda$ is the largest unrotated eigenvalue.

\section{Results}

\section{Stocking Rate}

On the average, ranchers rating individual question sublevels one at a time considered forage considerations more important in setting annual livestock stocking rates than other factors (Table 2). The important question was whether order and magnitude of ratings remained the same when correlations among variables were considered.

The largest correlation in the sublevels of the stocking rate question was between forage ( 0.38 ) and livestock considerations (Table 3). Smallest correlations were between other people's advice and all other variables except wildlife considerations. Two principal components with eigenvalues greater than 1.0 were extracted in the factor pattern matrix. The first 2 components explained $54 \%$ of the total variation in the original correlation matrix. After the reference axes were rotated orthogonally (Varimax procedure) the second component explained a 
Table 3. Correlation coefficients for variables measuring the importance of stocking rate factors, grazing program benefits, and weed/brush treatment techniques.

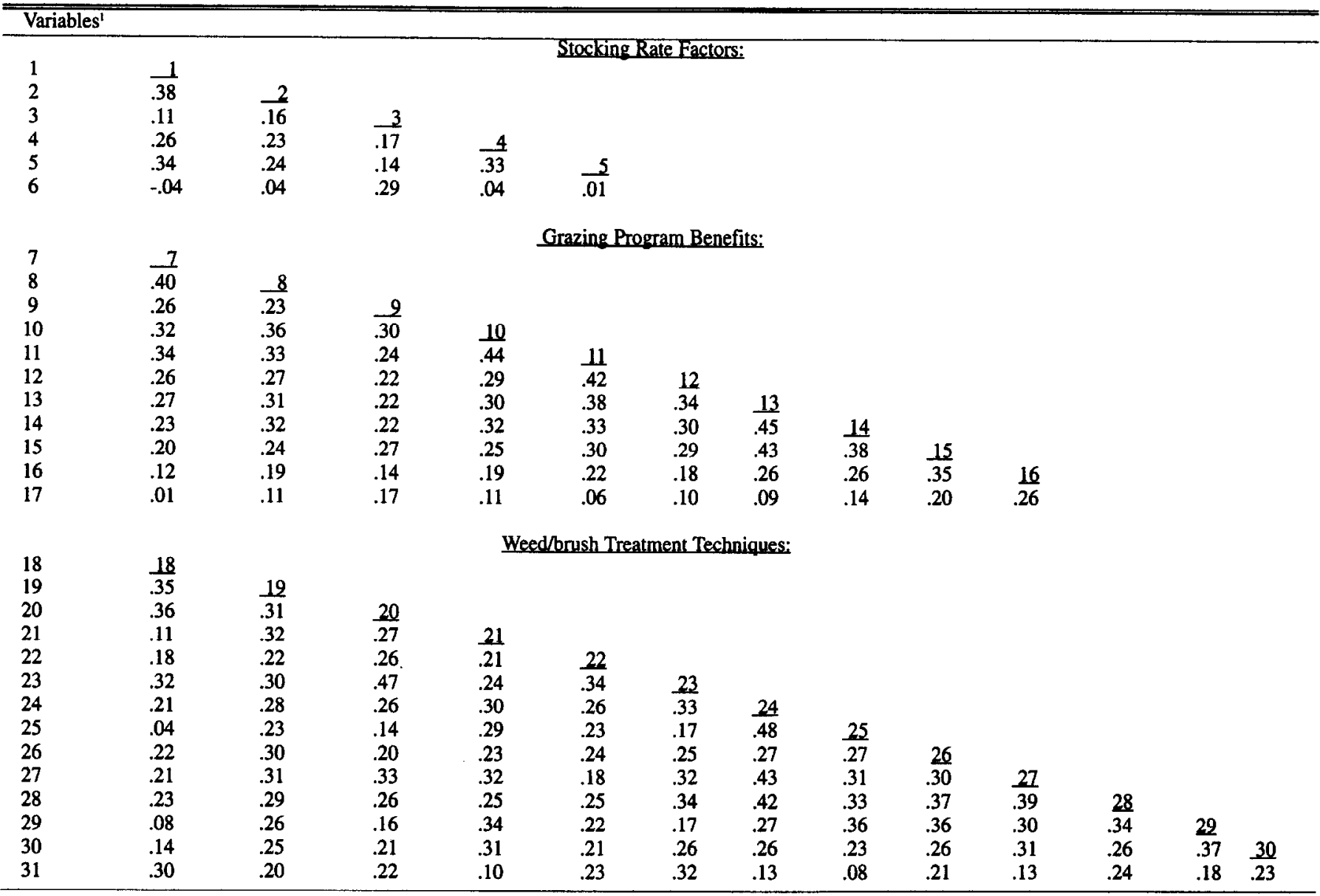

'See Table 1 for variable descriptions corresponding to numbers.

slightly larger portion of the common variance than before rotation (Table 4). Rotation of reference axes does not affect the amount of total variance explained by the components..

Variables for forage considerations, weather, livestock considerations, and past experience comprised the first component. Because of the high loadings of forage, weather and livestock factors on the first component, it was interpreted as Traditional Stocking Rate Factors which ranchers consider when making stocking rate decisions. The second component, with other people's advice and wildlife considerations in common, was interpreted as Nontraditional Stocking Rate Factors. Ranchers who scored relatively high on the questions about using other people's advice and wildlife considerations would score relatively low on the traditional variables associated with forage, weather, livestock, and past experience.

The reliability coefficient resulting from the scaled scoring was 0.597 , or $60 \%$. A score of $70 \%$ is generally acceptable. Therefore, the resulting scaled scoring may have some measurement error causing the reliability coefficient to be lower than expected.

\section{Grazing Programs}

For the grazing program question, the largest mean scores for importance of grazing program benefits were for improved amount or kind of forage and improved livestock performance (Table 2). Strongest correlations were between reduced feed purchases and reduced drought impact, between improved grazing distribution and improved livestock performance, and between reduced feed purchases and reduced labor requirement (Table 3).
Examination of the eigenvalues in the factor pattern matrix revealed two components with eigenvalues greater than 1.0 (Table 5). These 2 components explained $45 \%$ of the variance of the correlation matrix. Varimax rotation was performed to maximize high loadings on the 2 components and facilitate interpretation. Eight variables loaded highly on the first component and 3 variables on the second component. Interpretation of the first component, as in the stocking rate question, was that it was measuring Traditional Grazing Program Factors and the second component Nontraditional Grazing Program Factors. Variables for wildlife habitat and other people's approval were relegated to the second component as in the stocking rate question. The Reliability Coefficient calculated on the scoring coefficients suggests that the resulting scores would be highly reliable as independent variables in multiple regression analysis.

\section{Weed/Brush Techniques}

The cost of weed/brush treatment and kind, height, or density of brush/weeds were given the highest average importance rating by ranchers (Table 2). When correlations among the rancher's responses to question sublevels were considered, some patterns emerged (Table 3). Cost of treatment was moderately correlated with projected economic returns and brush kind, height, or density, but only midly correlated with advice from neighbors. Advice from agencies was moderately correlated with advice from neighbors and result demonstrations, but not with personal experience.

Two components were retained, per the Kaiser-Guttman rule (Loehlin 1987), and they explained $42 \%$ of the total variation in the original correlation matrix. After the Varimax rotation, the first prin- 
Table 4. Variable loadings on 2 principal components after Varimax rotation, and a reliability coefficient for the livestock stocking rate question.

\begin{tabular}{|c|c|c|c|c|}
\hline \multirow{2}{*}{$\begin{array}{l}\text { Com- } \\
\text { ponent }\end{array}$} & \multirow{2}{*}{ Variable } & \multirow[b]{2}{*}{ Communality } & \multicolumn{2}{|c|}{ Component Loadings } \\
\hline & & & 1 & 2 \\
\hline & Forage considerations & 0.568 & 0.749 & -0.087 \\
\hline \multirow[t]{3}{*}{1} & Weather & 0.442 & 0.694 & 0.039 \\
\hline & Livestock considerations & 0.620 & 0.657 & 0.101 \\
\hline & Past experience & 0.411 & 0.625 & 0.142 \\
\hline \multirow[t]{2}{*}{2} & Other people's advice & 0.483 & -0.092 & 0.831 \\
\hline & Wildlife considerations & 0.699 & 0.226 & 0.754 \\
\hline \multicolumn{2}{|c|}{ Eigenvalue } & 1.925 & 1.299 & \\
\hline \multicolumn{3}{|c|}{ Total variance explained by each component } & 32.08 & 21.66 \\
\hline \multirow{2}{*}{\multicolumn{3}{|c|}{$\begin{array}{l}\text { Common variance explained by each component } \\
\text { Reliability coefficient }\end{array}$}} & 59.70 & 40.30 \\
\hline & & & & 0.597 \\
\hline
\end{tabular}

cipal component explained $56 \%$ of the common variance explained by the 2 components. Variables associated with information sources loaded on component one and the economic variables loaded highly on componet 2 (Table 6). Thus, the first component was interpreted as Information Sources for Weed/brush Technology Adoption and the second component as Economic Impacts on Weed/brush Technology Adoption.

The reliability coefficient of the resulting scaled scoring was quite high at $83 \%$. This value indicated that the independent variable scores on the weed/brush question when used in regression analysis would have high reliability.

\section{Conclusions}

Each of the main categories under consideration; stocking rate factors, grazing program benefits, and weed/brush treatment techniques, exhibited two "new" variables explaining variation in rancher's responses to question sublevels. Stocking rate factors and grazing program factors appeared to follow the pattern of traditional and nontraditional components for each category. Traditional stocking rate management was defined by the perceived importance ranchers placed on forage considerations, weather, livestock considerations and past experience. Ranchers were able to recognize the importance of these factors in establishing livestock stocking rates evidenced by the common variance (62\%) explained by component 1 . Although the 6 factors queried in the stocking rate question appear to cover this ranching practice adequately, ranchers may have had additional factors upon which they rely in setting stocking levels. This observation is based upon the low level of reliability of the scaled scores. When presented with general knowledge about factors helpful in setting stocking rates, ranchers may be able to perceive the importance of certain stocking rate factors, but they may not adopt or utilize them.

Traditional grazing program management was defined by the perceived importance ranchers placed on improved livestock performance, improved amount or kind of forage, improved grazing distribution and increased or decreased forage use, among other reasons.

Perhaps this component should have been called something other than "traditional" because of the strong perception held by ranchers that utilization of a grazing program would effect an improvement in livestock performance. Both range and livestock factors are important considerations in designing grazing programs, but the primary purpose is to address deficiencies in plant health caused by environmental conditions or grazing management. Consequently, "traditional" grazing program views held by ranchers may not coincide with accepted research and extension recommendations and thus need to receive additional attention by change agents.
Table 5. Variable loadings on 2 principal components after Varimax rotation, and a reliability coefficient for the grazing program question.

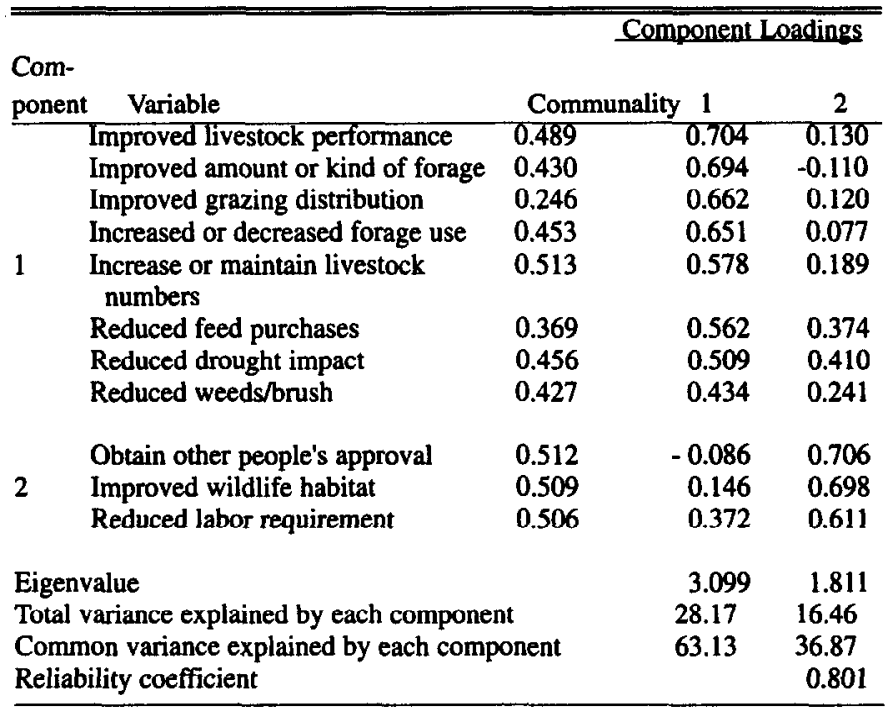

Nontraditional components of stocking rate and grazing program management had two variables in common, wildlife factors and other people's approval. Ranchers who responded similarly to wildlife considerations and other people's opinions (component 2), but differently to traditional stocking rate and grazing management, were relegated to a dimension (i.e., second component) explaining a relatively small portion of the total variance of all components. Ranchers may perceive these two factors as less important for very different reasons.

The components for weed/brush control techniques appeared to be measuring dimensions other than traditional/nontraditional. The ques-

Table 6. variable loadings on 2 principal components after Varimax rotation, and a reliability coefficient for the weed/brush treatment question.

Com-

Component Loadings

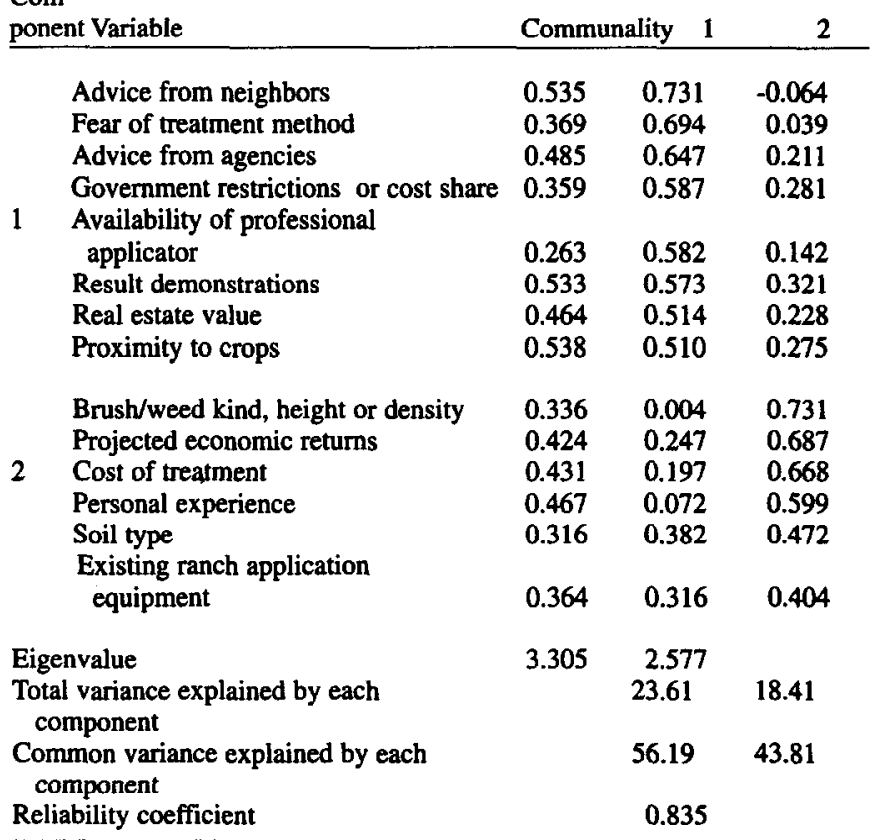


tion that was asked of ranchers was what variables they considered important in deciding the types of techniques to use in weed/brush control. It appears that ranchers considered this question to be asking for more technical information than in the stocking rate or grazing program questions (e.g., information variables loaded highly on component 1 and not on component 2). In actuality, the technology required in weed/brush control may not be any more complex than that which should be applied to balance forage supply with animal demand. However, a cluster of ranchers responded similarly to information sources about control techniques. Importance given to advice from neighbors and fear of treatment method should concern researchers and change agents alike. Both of these variables have the potential for restricting adoption of weed/brush technology. Researchers have generally found that advice from neighbors is less likely to be the latest information concerning technology. Combined with an apprehension about using control techniques (i.e., safety or environmental concerns), research recommendations may not be reaching many rangeland operators.

It remains to be seen how ranchers who similarly use information sources transmit that information into decision-making about resources. Results of the principal component analysis appear to indicate some misconceptions in either the knowledge base or the application of knowledge by rangeland operators. The weakness may lie in the diffusion link between scientific knowledge and production agriculture. Unfortunately, the full impact of decision-making components cannot be assessed until they are analyzed against some response outcome (see Rowan, White and Conner 1994).

\section{Literature Cited}

Carmines, E.G. and R.A. Zeller. 1979. Reliability and validity assessment. Sage Publications, Beverly Hills, Calif.

Cronbach, LJ. 1951. Coefficient alpha and the internal structure of tests. Psychometrika 16:297-334.

Dunteman, G.H. 1989. Principal component analysis. Sage Publications, Newbury Park, Calif.

Hanselka, C.W., A. McGinty, B.S. Rector, R.C. Rowan, and L.D. White. 1990. Grazing and brush management on Texas rangelands: an analysis of management decisions. Texas Agric. Ext. Serv. Texas A\&M Univ., College Station.

Loehlin, J.C. 1987. Latent variable models: an introduction to factor, path and structural analysis. Lawrence Erlbaum Associates, Hillsdale, New Jersey.

Rowan, R.C. and L.D. White. 1994. Regional differences among Texas rangeland operators. J. Range Manage. 47:338-345.

Rowan, R.C., L.D. White, and J.R. Conner. 1994. Understanding cause/effect relationships in stocking rate change over time. J. Range Manage. 47:349-354. 